\title{
ANALISA KEANDALAN POMPA SENTRIFUGAL MENGGUNAKAN ANALYSIS OF VARIANT DAN RELIABILITY BLOCK DIAGRAM BERDASARKAN IDENTIFIKASI KEGAGALAN MELALUI FAULT TREE ANALYSIS DAN ROOT CAUSE ANALYSIS
}

\author{
Koko D. Langga ${ }^{1 *}$, M. Sabri ${ }^{2}$, Alfian $\mathrm{Hamsi}^{3}$, Syahrul $\mathrm{Abda}^{4}$, Indra $^{5}$ \\ 1,2,3,4,5 Departemen Teknik Mesin, Fakultas Teknik, Universitas Sumatera Utara \\ Email: kokodwilangga@gmail.com
}

\begin{abstract}
Centrifugal pump is a machine for moving fluid. The pump moves the fluid from a lowpressure place to a place with higher pressure, to overcome this pressure difference, energy is needed. This machine is a very important machine in the Regional Water Company (PDAM) because it is a major component as a channel for water. The purpose of this study was to identify failures in centrifugal pumps using fault tree analysis (FTA) and root cause analysis (RCA), and to use analysis of variants (ANOVA) and reliability block diagrams (RBD) to determine the value of reliability. Centrifugal pump machines are located in the Tirtasari Regional Water Supply Company (PDAM), Binjai Kota, Binjai. At each factory or company maintenance management greatly affects production and system efficiency.
\end{abstract}

Keywords: Centrifugal pumps, failure, reliability, maintenance

\section{ABSTRAK}

Pompa Sentrifugal adalah mesin untuk menggerakan fluida. Pompa menggerakan fluida dari tempat bertekanan rendah ke tempat dengan tekanan yang lebih tinggi, untuk mengatasi perbedaan tekanan ini maka diperlukan tenaga (energi). Mesin ini merupakan mesin yang sangat penting pada Perusahaan Daerah Air Minum (PDAM) karena menjadi komponen utama sebagai menyalur air. Tujuan penelitian ini adalah mengidentifikasi kegagalan-kegagalan pada pompa sentrifugal dengan menggunakan fault tree analysis (FTA) dan root cause analysis (RCA), serta menggunakan analysis of variant (ANOVA) dan reliability block diagram (RBD) untuk menentukan nilai kehandalan. Mesin pompa sentrifugal terdapat di pabrik Perusahaan Daerah Air Minum (PDAM) Tirtasari, Binjai Kota, Binjai. Pada setiap pabrik ataupun perusahaan manajemen pemeliharaan sangat mempengaruhi produksi dan efisiensi sistem.

Kata Kunci: Pompa Sentrifugal, kegagalan, kehandalan, pemeliharaan 


\section{Pendahuluan}

Pompa adalah salah satu jenis mesin fluida yang berfungsi untuk memberikan energi kepada fluida, dimana fluida adalah zat cair, sehingga zat cair tersebut dapat dipindahkan dari suatu tempat ke tempat lainnya. Dalam operasinya pompa perlu digerakkan oleh suatu penggerak mula, dalam hal ini dapat digunakan motor listrik maupun motor torak. Dalam menjalankan fungsinya tersebut, pompa mengubah energi gerak poros untuk menggerakkan sudu-sudu (impeller) menjadi energi tekanan pada fluida

Salah satu jenis pompa yang banyak digunakan adalah pompa sentrifugal. Pompa sentrifugal Merupakan pompa yang sangat umum digunakan untuk pemompaan fluida seperti air, minyak dan lain - lain di berbagai industri. Dalam dunia industri, atau suatu perusahaan yang berhubungan dengan air sepertei PDAM sebagai salah satu penyedia ari bersih sudah pasti menggunakan pompa sebagai alat utama sebagai penyalur air.

Seperti kita ketahui bahwa pompa akan selalu bekerja hampir 24 jam untuk mendistribusikan air dan kerusakan sudah pasti tidak dapat di hindari. Maka dari itu penulis tertarik untuk mengetahui sebanyak apa kegagalan yang terjadi dan melihat apakah kerusakan tersebut dapat dikurangi dengan menggunakan beberapa metode jika di terapkan dalam penggunaaan pompa tersebut.

\section{Metode}

Pengambilan data di lakukan di Perusahaan Ait Minum Daerah (PDAM) BInjai Kota pada 1 Februari 2019. Jenis metode yang digunakan dalam pembahasan Analisa kehandalan ini menggunakan Analysis of Variant (Anova) dan Reliability Block Diagram $(R B D)$ berdasarkan identifikasi masalah kegagalan memalui Fault Tree Analysis dan Root Couse Analysis,

\subsection{Analysis of Variance (ANOVA)}

Analisis varians (analysis of variance, ANOVA) adalah suatu metode analisis statistika yang termasuk ke dalam cabang statistika inferensi. Dalam literatur Indonesia metode ini dikenal dengan berbagai nama lain, seperti analisis ragam, sidik ragam, dan analisis variansi. Ia merupakan pengembangan dari masalah Behrens-Fisher, sehingga ujiF juga dipakai dalam pengambilan keputusan. Analisis varians pertama kali diperkenalkan oleh Sir Ronald Fisher, bapak statistika modern. Dalam praktek, analisis 
varians dapat merupakan uji hipotesis (lebih sering dipakai) maupun pendugaan (estimation, khususnya di bidang genetika terapan).

\subsection{Reliability Block Diagram (RBD)}

Reliability Block Diagram (RBD) adalah metode diagram untuk menunjukkan bagaimana komponen keandalan kontribusi bagi keberhasilan atau kegagalan sistem yang kompleks. RBD juga dikenal sebagai diagram ketergantungan (DD).

Sebuah RBD atau DD diambil sebagai rangkaian blok terhubung dalam konfigurasi paralel atau seri. Setiap blok merupakan komponen dari sistem dengan tingkat kegagalan. jalur paralel yang berlebihan, yang berarti bahwa semua jalur paralel harus gagal. Sebaliknya, kegagalan sepanjang jalan seri menyebabkan seluruh jalan seri gagal.

\subsection{Fault Tree Analysis (FTA)}

Fault Tree Analysis (FTA) adalah salah satu teknik yang dapat diandalkan, dimana kegagalan yang tidak diinginkan, diatur dengan cara menarik kesimpulan dan dipaparkan dengan gambar (Ansori dan Mustajib. 2013:40). Fault tree analysis adalah salah satu diagram satu arah dan menghubungkan informasi yang dikembangkan dalam analisa cara kegagalan dan akibatnya (failure mode and effect analysis, FMEA). (Ebeling, 1997)

Langkah-langkah membangun FTA:

1. Mendefinisikan kecelakaan

2. Mempelajari sistem dengan cara mengetahui spesifikasi peralatan, lingkungan kerja dan prosedur operasi.

3. Mengembangkan pohon kesalahan.

\subsection{Root Cause Analysis (RCA)}

Pengertian Root cause analysis (RCA) adalah proses pemecahan masalah untuk melakukan investigasi ke dalam suatu masalah, kekhawatiran atau ketidak sesuaian masalah yang ditemukan. RCA membutuhkan investigator untuk menemukan solusi atas masalah mendesak dan memahami penyebab fundamental atau mendasar suatu situasi dan memperlakukan masalah tersebut dengan tepat, sehingga mencegah terjadinya kembali permasalahan yang sama. Oleh karena itu mungkin melibatkan pengidentifikasian dan pengelolaan proses, prosedur, kegiatan, aktivitas, perilaku atau kondisi (British Retail Consortium, 2012). 


\section{Hasil dan Pembahasan}

Berdasarkan pengamatan yang telah dilakukan mengenai proses kerja pompa sentrifugal, dilakukan deskripsi bentuk kegagalan yang dapat dilihat pada tabel dibawah ini :

Tabel 3.1 Bagian - bagian pompa sentrifugal

\begin{tabular}{|c|c|c|}
\hline No & Bagian Pompa & Fungsi \\
\hline 1 & Seal ring & $\begin{array}{l}\text { Untuk memperhalus pengoperasian dan mengurangi } \\
\text { keausan, Menjaga kebocoran pelumas (lubrikasi). } \\
\text { Menjaga kotoran dan material lain masuk ke sistem. } \\
\text { Memberikan batasan cairan supaya tidak tercampur. }\end{array}$ \\
\hline 2 & Packing & $\begin{array}{l}\text { digunakan untuk mencegah dan mengurangi } \\
\text { kebocoran cairan dari casing pompa yang } \\
\text { berhubungan dengan poros, biasanya terbuat dari } \\
\text { Asbes atau Teflon. }\end{array}$ \\
\hline 3 & Poros & $\begin{array}{l}\text { Poros berfungsi untuk meneruskan momen puntir dari } \\
\text { penggerak selama beroperasi dan tempat tumpuan } \\
\text { impeller dan bagian-bagian lainnya yang berputar. }\end{array}$ \\
\hline 4 & Discharge nozzle & $\begin{array}{l}\text { bagian dari pompa yang berfungsi sebagai tempat } \\
\text { keluarnya fluida hasil pemompaan. }\end{array}$ \\
\hline 5 & Kasing & $\begin{array}{l}\text { merupakan bagian luar dari pompa yang berfungsi } \\
\text { sebagai pelindung elemen di dalamnya. }\end{array}$ \\
\hline 6 & Impeller & $\begin{array}{l}\text { berfungsi untuk mengubah energi mekanis dari pompa } \\
\text { menjadi energi kecepatan pada cairan/fluida yang } \\
\text { dipomparan secara kontinyu, sehingga cairan pada sisi } \\
\text { isap secara terus menerus akan masuk mengisi } \\
\text { kekosongan akibat perpindahan dari cairan/fluida } \\
\text { yang masuk sebelumnya. }\end{array}$ \\
\hline 7 & Bearing & $\begin{array}{l}\text { Bantalan berfungsi untuk menumpu atau menhan } \\
\text { beban dari poros agar dapat berputar. Bearing juga } \\
\text { berfungsi untuk memperlancar putaran poros dan } \\
\text { menahan poros agar tetap pada tempatnya, sehingga }\end{array}$ \\
\hline
\end{tabular}




\begin{tabular}{|l|l|l|}
\hline & & kerugian gesek dapat diperkecil. \\
\hline 8 & Eye of impeller & bagian masuk pada arah hisap impeller. \\
\hline
\end{tabular}

Berdasarkan jenis kegagalan pada proses pompa sentrifugal, maka selanjutnya dapat membuat pohon kesalahan (Fault Tree), studi kasus kali ini hanya akan membahas kegagalan pada bagian rumah impler dan bagian dalamnya, Untuk dapat menghitung tingkat kegagalan dari Fault tree analysis diatas maka dapat digunakan asumsi nilai keparahan (Severity) pada setiap kemungkinannya, adapun nilai tersebut dijelaskan sebagai berikut :

Tabel 3.2 Skala Severity

\begin{tabular}{|c|l|l|}
\hline Ranking & \multicolumn{1}{|c|}{ Severity } & \multicolumn{1}{c|}{ Deskripsi } \\
\hline 0.09 & $\begin{array}{l}\text { Berbahaya tanpa } \\
\text { peringatan }\end{array}$ & $\begin{array}{l}\text { Kegagalan sistem yang menghasilkan efek sangat } \\
\text { berbahaya }\end{array}$ \\
\hline 0.08 & $\begin{array}{l}\text { Berbahaya dengan } \\
\text { peringatan }\end{array}$ & Kegagalan sistem yang menghasilkan efek berbahaya \\
\hline 0.07 & Sangat tinggi & Sistem tidak beroperasi \\
\hline 0.06 & Tinggi & $\begin{array}{l}\text { Sistem beroperasi tetapi tidak dapat dijalankan } \\
\text { secara penuh }\end{array}$ \\
\hline 0.05 & Sedang & $\begin{array}{l}\text { Sistem beroperasi dan aman tetapi mengalami } \\
\text { penurunan performa sehingga mempengaruhi output }\end{array}$ \\
\hline 0.04 & Rendah & Mengalami penurunan kinerja secara bertahap \\
\hline 0.03 & Sangat rendah & Efek yang kecil pada performa sistem \\
\hline 0.02 & Kecil & Sedikit berpengaruh pada kinerja sistem \\
\cline { 2 - 3 } & Sangat kecil & Efek yang diabaikan pada kinerja sistem \\
\hline 0.01 & Tidak ada efek & Tidak ada efek \\
\hline
\end{tabular}

\subsection{Pembahasan Dengan Fault Tree Analysis}

Setelah melakukan pemberian asumsi pada setiap komponen dengan metode fault tree analysis maka didapat nilai kegagalan pada komponen yang bisa dilihat pada table berikut:

Tabel 3.3 gegagalan komponen

\begin{tabular}{|c|l|c|c|}
\hline No & \multicolumn{1}{|c|}{ Kegagalan Komponen } & P & $\%$ \\
\hline 1 & Kegagalan seal ring & 0.052375 & $5.23 \%$ \\
\hline 2 & Kegagalan poros & 0.01099 & $1.09 \%$ \\
\hline 3 & Kegagalan packing & 0.0595 & $5.95 \%$ \\
\hline 4 & Kegagalan casing impeller & 0.0199 & $1.99 \%$ \\
\hline 5 & Kegagalan impeler & 0.01248 & $1.24 \%$ \\
\hline
\end{tabular}




\begin{tabular}{|l|l|c|c|}
\hline 6 & Kegagalan bearing & 0.04125 & $4.12 \%$ \\
\hline
\end{tabular}

\subsection{Pengujian Dengan ANOVA}

Untuk melakukan pengujian anova maka ada syarat yang harus dipenuhi, yaitu:

1. Sampel berasal dari kelompok yang independen.

2. Data masing-masing kelompok berdistribusi normal

3. Varian antar kelompok harus homogen.

Tabel 3.4 Test of Normality pada SPSS

Tests of Normality

\begin{tabular}{|l|l|r|r|r|r|r|r|}
\hline & \multirow{3}{*}{} & \multicolumn{3}{|c|}{ Kolmogorov-Smirnov $^{\mathrm{a}}$} & \multicolumn{3}{|c|}{ Shapiro-Wilk } \\
\cline { 2 - 8 } & komponen & Statistic & \multicolumn{1}{c|}{ Df } & \multicolumn{1}{c|}{ Sig. } & Statistic & \multicolumn{1}{c|}{ df } & \multicolumn{1}{c|}{ Sig. } \\
\hline Nilai & seal ring & .235 & 20 & .005 & .764 & 20 & .000 \\
& paking & .217 & 20 & .014 & .945 & 20 & .296 \\
& poros & .263 & 20 & .001 & .823 & 20 & .002 \\
kasing & .204 & 20 & .028 & .856 & 20 & .007 \\
impeler & .373 & 20 & .000 & .653 & 20 & .000 \\
bearing & .188 & 20 & .063 & .920 & 20 & .097 \\
\hline
\end{tabular}

a. Lilliefors Significance Correction

Jika dilihat pada tebel 3.4. Pada uji kolmogorov-Smirnov pada kolom signifikan (disingkat sig.) nilainya adalah dibawah $<0.05$ dan hanya satu asumsi yang nilai H0nya diterima, kmudian disetiap kolom nilainya bervariatif. Sedangkan pada uji Shapiro-wilk pada kolom signifikannya nilai bervariatif dibawah ni $<0.05$ dan hanya dua asumsi yang nilainya terdistribusi normal.

Tabel 3.5 Test of Homogenity of Variances

Test of Homogeneity of Variances nilai

\begin{tabular}{|c|c|c|c|}
\hline $\begin{array}{l}\text { Levene } \\
\text { Statistic }\end{array}$ & df1 & df2 & Sig. \\
\hline 1.462 & 5 & 114 & .208 \\
\hline
\end{tabular}


Dari tabel 3.5 Test of Homegeneity of Variances terlihat bahwa hasil uji menunjukan bahwa varian tersebut sama $(\mathrm{P}$-value $=0.208)$ atau $0.208>0.05$, sehingga uji Anova valid untuk menguji hubungan ini.

Tabel 3.6 ANOVA

ANOVA
nilai
\begin{tabular}{|l|r|r|r|r|r|}
\hline & \multicolumn{1}{|c|}{ Sum of } & & & & \\
& Squares & df & Mean Square & F & Sig. \\
\hline Between Groups & .018 & 5 & .004 & 16.232 & .000 \\
Within Groups & .025 & 114 & .000 & & \\
Total & .043 & 119 & & & \\
\hline
\end{tabular}

Pada tabel 3.6, pada kolom Sig. diperoleh nilai P $(\mathrm{P}-\mathrm{value})=0.000$. Dengan demikian pada taraf nyata $=0.05$ menolak Ho, sehingga kesimpulan yang didapatkan adalah ada perbedaan yang bermakna rata-rata nilai terhadap setiap komponen yang telah diberi asumsi.

\subsection{Meningkatkan kehandalan (RBD)}

Untuk mencari nilainya, yang harus kita lakukan adalah mengambil beberapa data. Data itu berupa kerusakan apa saja yang pernah terjadi, pada data tersebut didapat waktu kerusakan. Setelah itu kita tentukan berapa lama mesin bekerja, penulis mengambil 200, 300, 400 dan 500 jam.

Adapun rumus untuk menghitung nilai reliability tersebut. Berikut rumusnya:

$$
M T B F=\frac{\text { Operating Time }}{\text { Failure }}
$$

Keterangan:

- MTBF (Mean Time Between Failure): menunjukkan tentang seberapa handalnya peralatan/ mesin operasi dalam menghasilkan produk, yang dilihat dari waktu rata-rata peralatan/ mesin itu akan berfungsi mulai dari satu repair/kerusakan sampai ke repair/ kerusakan berikutnya.

- Operating Time: Lama mesin bekerja

- Failure:Seberapa banyak kegagalan terjadi selama operating time. 


$$
\begin{array}{ll}
\text { MTBF bearing } & =\frac{4800 \text { hours }}{5}=960 \text { hours } \\
\text { MTBF seal ring } & =\frac{4800 \text { hours }}{6}=800 \text { hours } \\
\text { MTBF impeller } & =\frac{4800 \text { hours }}{1}=4800 \text { hours } \\
\text { MTBF poros } & =\frac{4800 \text { hours }}{1}=4800 \text { hours } \\
\text { MTBF paking } & =\frac{4800 \text { hours }}{2}=2400 \text { hours } \\
\text { MTBF kasing } & =\frac{4800 \text { hours }}{0}=0 \text { hours }
\end{array}
$$

Menghitung Failure Rate ( $\lambda$ - lamda) maka dapat menggunakan rumus sebagai berikut:

$$
\lambda=\frac{1}{\mathrm{MTBF}}
$$

Berdasarkan rumus diatas maka untuk mengetahui failure rate pada suatu komponen dapat dihitung sebagai berikut:

$$
\begin{array}{lll}
\lambda \text { bearing } & =\frac{1}{960} & =0.00104 \\
\lambda \text { seal ring } & =\frac{1}{800} & =0.00125 \\
\lambda \text { impeller } & =\frac{1}{4800} & =0.00021 \\
\lambda \text { poros } & =\frac{1}{4800} & =0.00021 \\
\lambda \text { paking } & =\frac{1}{2400} & =0.00042 \\
\lambda \text { kasing } & & =\frac{1}{0} \quad=0
\end{array}
$$

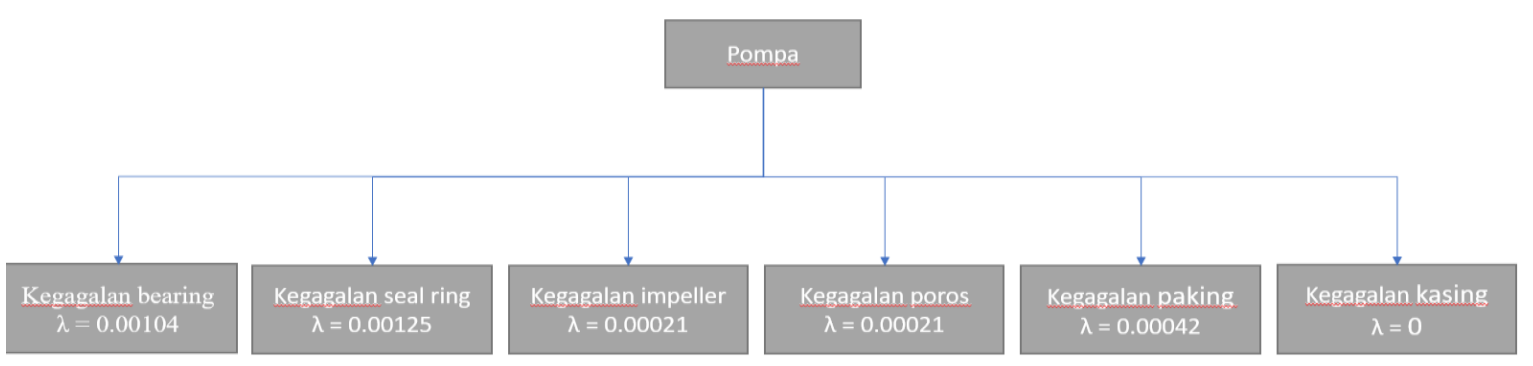

Gambar 4.10 Failure rate komponen 
Selanjutnya adalah perhitungan Reliability-nya berdasarkan jam operasi, jam operasi yang digunakan adalah 200, 300, 400 dan 500 jam. Keandalan masing - masing komponen dapat dihitung dengan rumus sebagai berikut:

$$
\mathrm{R}(\mathrm{t})=\boldsymbol{e}^{-(\lambda)(\mathrm{t})}
$$

$$
\begin{array}{ll}
\text { Dimana: } & \mathrm{R}(\mathrm{t})=\text { keandalan (Reliability), peralatan beroperasi pada waktu } \mathrm{t} \\
\boldsymbol{e} & =2.718281828459045 \\
\lambda & =\text { failure rate } \\
\mathrm{t} & =\text { Waktu operasi yang diinginkan }
\end{array}
$$

\begin{tabular}{|c|c|c|c|c|c|}
\hline $\mathrm{R} 1=0.8119$ & $R 2=0.7788$ & R3 = 0.9592 & $R 4=0.9592$ & $R 5=0.9201$ & $\mathrm{R} 6=1$ \\
\hline bearing & seal ring & impeller & poros & paking & kasing \\
\hline
\end{tabular}

a. Perhitungan berdasarkan 200 jam operasi

Gambar 4.11 Perhitungan Reliability berdasarkan 200 jam operasi

Rsys $=\mathrm{R}_{1} \times \mathrm{R}_{2} \times \mathrm{R}_{3} \times \mathrm{R}_{4} \times \mathrm{R}_{5} \times \mathrm{R}_{6}$

Rsys $=0.8119 \times 0.7788 \times 0.9592 \times 0.9592 \times 0.9201 \times 1$

Rsys $=0.5352$

b. Perhitungan berdasarkan 300 jam operasi

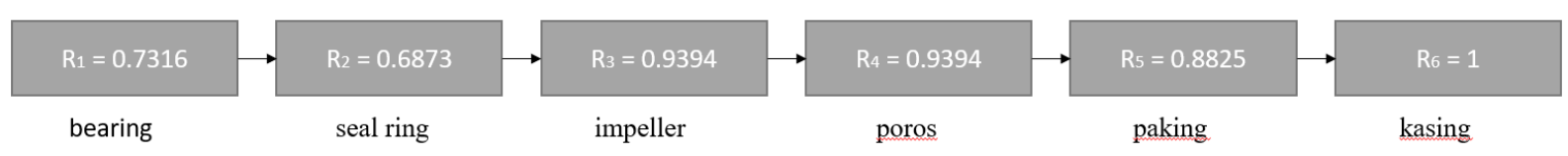

Gambar 4.12 Perhitungan Reliability berdasarkan 300 jam operasi

$$
\begin{aligned}
& \text { Rsys }=R_{1} \times R_{2} \times R_{3} \times R_{4} \times R_{5} \times R_{6} \\
& \text { Rsys }=0.7316 \times 0.6875 \times 0.9394 \times 0.9394 \times 0.8825 \times 1 \\
& \text { Rsys }=0.3916
\end{aligned}
$$

c. Perhitungan berdasarkan 400 jam operasi

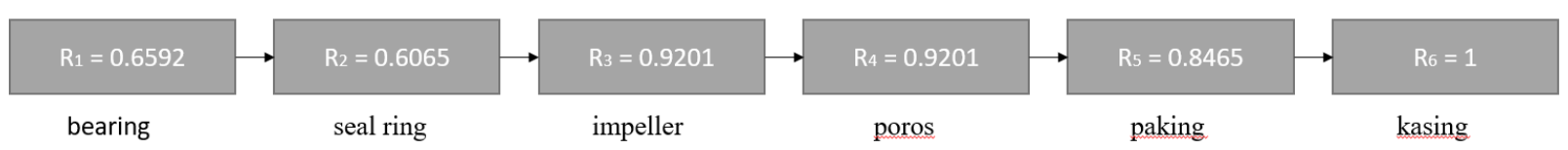

Gambar 4.13 Perhitungan Reliability berdasarkan 400 jam operasi

$$
\begin{aligned}
& \text { Rsys }=R_{1} \times R_{2} \times R_{3} \times R_{4} \times R_{5} \times R_{6} \\
& \text { Rsys }=0.6592 \times 0.6065 \times 0.9201 \times 0.9201 \times 0.8465 \times 1 \\
& \text { Rsys }=0.2865
\end{aligned}
$$

d. Perhitungan berdasarkan 500 jam operasi 


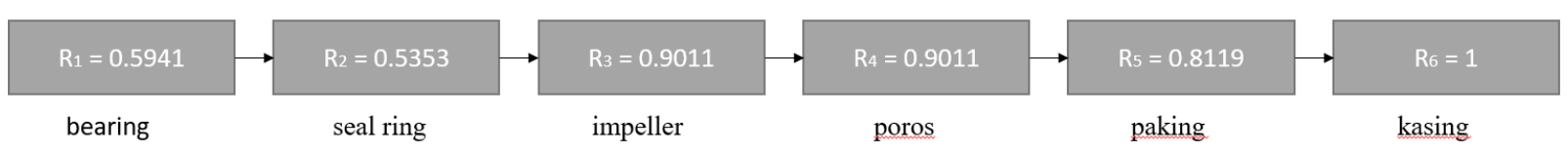

Gambar 4.14 Perhitungan Reliability berdasarkan 500 jam operasi

$$
\begin{aligned}
& \text { Rsys }=R_{1} \times R_{2} \times R_{3} \times R_{4} \times R_{5} \times R_{6} \\
& \text { Rsys }=0.5941 \times 0.53526 \times 0.9011 \times 0.9011 \times 0.8119 \times 1 \\
& \text { Rsys }=0.2096
\end{aligned}
$$

Maka didapat nilai kehandalan pada pompa adalah sebagai berikut: $53,52 \%$ apabila digunakan selama 200 jam operasi, 39,16\% apabila digunakan selama 300 jam operasi, 28,65\% apabila digunakan selama 400 jam operasi dan menurun menjadi 20,96\% apabila digunakan selama 500 jam.

\subsection{Fish Bone RCA}

Analisa ini dilakukan dengan pengamatan secara langsung dilapangan dan melakukan wawancara terhadap karyawan yang terkait pada penelitian ini, yaitu antara lain operator, bagian teknik dan bagian quality control. Hasil wawancara tersebut merupakan salah satunya kemungkinan penyebab dari sulitnya tercapai target nilai kehandalan yang diinginkan. Untuk memperoleh hasil analisa yang sesuai, dibutuhkan tools yang relevan dengan data yang sudah dikumpulkan.

Dalam wawancara tersebut diambil beberapa parameter yaitu material, mesin, manusia dan metode, dapat dilihat pada gambar dibawah ini

Diagram sebab akibat diatas mengidentifikasi penyebab berdasarkan 4 kategori yaitu:
1. Manusia
2. Mesin
3. Metode
4. Material

\section{Kesimpulan}

Dari hasil analisa data yang dilakukan pada pompa sentrifugal di PDAM Tirtasari maka dapat disimpulkan:

1. Pompa Sentrifugal berfungsi untuk memindahkan atau mendistribusikan air yang memanfaatkan gaya sentrifugal dengan mengubah energi kinetis 
(kecepatan) cairan menjadi energi potensial (dinamis) melalui suatu impeller yang berputar dalam casing.

2. Setelah dilakukan identifikasi menggunakan metode fault tree analysis maka di dapat komponen kritis yang potensi kegagalannya, yaitu:

\begin{tabular}{|c|l|c|c|}
\hline No. & \multicolumn{1}{|c|}{ Kegagalan Komponen } & P & $\%$ \\
\hline 1 & Kegagalan seal ring & 0.052375 & $5.23 \%$ \\
\hline 2 & Kegagalan poros & 0.01099 & $1.09 \%$ \\
\hline 3 & Kegagalan packing & 0.0595 & $5.95 \%$ \\
\hline 4 & Kegagalan casing impeller & 0.0199 & $1.99 \%$ \\
\hline 5 & Kegagalan impeler & 0.01248 & $1.24 \%$ \\
\hline 6 & Kegagalan bearing & 0.04125 & $4.12 \%$ \\
\hline
\end{tabular}

3. Dari proses perhitungan menggunakan Analysis of Varian (ANOVA) dan Relibiality Block Diagram (RBD) maka didapat kehandalan sistem dalam Pompa Sentrifugal adalah 53,52\% apabila digunakan selama 200 jam operasi, $39,16 \%$ apabila digunakan selama 300 jam operasi, 28,65\% apabila digunakan selama 400 jam operasi, dan menurun menjadi 20,96\% apabila digunakan selama 500 jam.

\section{Referensi}

[1] Ansori, Nachnul dan Mustajib, M. Imron. 2016.Sistem Perawatan Terpadu (Integrated Maintenance System). Yogyakarta: Graha Ilmu.

[2] Arina F, Ferdinant PF, Hamid A. 2013. "Penentuan keandalan dengan menggunakan Reliability Block Diagram (RBD) yang berkonfigurasi redundant pada mesin boiler di PT.X.” Seminar Nasional IENACO, ISSN 2337-4349.

[3] D. H. Stamatis. 2003. Failure Mode and Effect Analysis: FMEA from Theory to Execution. Milwaukee, Wisconsin: ASQ Quality Press.

[4] Dogget, A. M. 2005. Root Cause Analysis: A Framework for Tool Selection. The Quality Management Journal, 35

[5] Dwi Priyanta. 2000. Keandalan dan Perawatan. Surabaya: Institut Teknologi Surabaya.

[6] Gulati, Ramesh dan Smith, Rick. 2012. Maintenance and Reliability Best Practice. New York: Industrial Press. 
[7] Kister, Timothy C dan Hawkins, Bruce. 2006.Maintenance Planning and Scheduling Handbook: Streamline Your Organization for a Lean Environment. Butterworth-Heinemann.

[8] Gulati,Ramesh dan Smith, Rick. 2012. Maintenance and Reliability Best Practice. New York: Industrial Press.

[9] Kister, Timothy $\mathrm{C}$ dan Hawkins, Bruce. 2006. Maintenance Planning and Scheduling Handbook: Streamline Your Organization for a Lean Environment. Butterworth-Heinemann. 